\title{
Explaining Suicide in an Urban Slum of Mumbai, India
}

\section{Citation}

Parkar, Shubhangi R., Balkrishna Nagarsekar, and Mitchell G. Weiss. 2009.

“Explaining Suicide in an Urban Slum of Mumbai, India." In Crisis 30, no. 4: 192-201. doi:10.1027/0227-5910.30.4.192.

\section{Published Version}

doi:10.1027/0227-5910.30.4.192

\section{Permanent link}

http://nrs.harvard.edu/urn-3:HUL.InstRepos:34864850

\section{Terms of Use}

This article was downloaded from Harvard University's DASH repository, and is made available under the terms and conditions applicable to Other Posted Material, as set forth at http:// nrs.harvard.edu/urn-3:HUL.InstRepos:dash.current.terms-of-use\#LAA

\section{Share Your Story}

The Harvard community has made this article openly available.

Please share how this access benefits you. Submit a story.

\section{Accessibility}




\section{Explaining suicide in an urban slum of Mumbai: findings from sociocultural autopsy}

Shubhangi R. Parkar ${ }^{1}$, Balkrishna Nagarsekar ${ }^{1}$, and Mitchell G. Weiss ${ }^{2}$

Manuscript accepted for publication in

Crisis

In Press

${ }^{1}$ Department of Psychiatry, KEM Hospital and Seth GS Medical College, Mumbai, India

${ }^{2}$ Department of Public Health and Epidemiology, Swiss Tropical Institute and University of Basel, Switzerland 


\title{
Explaining suicide in an urban slum of Mumbai: findings from sociocultural autopsy
}

\begin{abstract}
Background. Health demographic mortality studies use verbal autopsies to identify suicide as a cause of death. Psychological autopsies focus almost exclusively on associated high-risk psychiatric disorders. New approaches considering contextual factors are needed for preventing suicide and promoting mental health.
\end{abstract}

Aims. With reference to social, cultural and environmental conditions, and challenges of life in the Malavani slum of Mumbai, this study examined explanations of suicide reported by surviving family members or close friends.

Methods. An EMIC (Explanatory Model Interview Catalogue) interview based on a cultural epidemiological framework considered underlying problems, perceived causes, and sociocultural contexts. It was administered to survivors of 76 people who died by suicide (56.6\% women).

Results. Accounts of underlying problems typically referred to various aspects of tension (73.7\%). Perceived causes often identified multiple factors.

Sociocultural contexts of suicide included victimization of women, personal and social impact of problem drinking, marital problems, physical health problems, mental tension, possession and sorcery. Women were particularly vulnerable to the impact of problem drinking by a spouse or father.

Conclusions. This study demonstrates the value of an approach to sociocultural autopsy examining local contexts and explanations of suicide. Findings highlight needs for both mental health services and culturally sensitive social interventions.

Key words: Suicide; urban mental health; verbal autopsy; psychological autopsy; cultural epidemiology 


\section{Affiliations, Addresses, and Biographies}

(a) Corresponding Author: Name and complete address, including E-mail and telephone and telefax numbers of the corresponding author

Dr. Shubhangi R. Parkar

Department of Psychiatry

KEM Hospital and Seth GS Medical College

Parel

Mumbai 400012

India

Email: $\quad$ pshubhangi@gmail.com

Telephone: $\quad$ +9122 24136051

Telefax: $\quad$ +912224186662

\section{(b) Names and affiliations of all authors}

Shubhangi R. Parkar, Department of Psychiatry, KEM Hospital and Seth GS Medical College, Mumbai, India

Balkrishna Nagarsekar, HNE Health Service, New Lambton, NSW, Australia.

Mitchell G. Weiss, Department of Public Health and Epidemiology, Swiss Tropical Institute and University of Basel, Switzerland

\section{(c) A brief biography (up to 50 words) for each author}

\section{Shubhangi R. Parkar}

Shubhangi Parkar heads the Department of Psychiatry at the KEM Hospital and Seth GS Medical College, the leading academic medical and public health institute of the Mumbai Municipal Corporation. Working in both hospital and community settings, she has developed programmes on suicide prevention, geriatric psychiatry, addictions and women's mental health.

\section{Balkrishna Nagarsekar}

Balkrishna Nagasekar is a former postgraduate resident in psychiatry at the KEM Hospital and Seth GS Medical College. After training in Mumbai and with field research experience in community mental health, he is currently working as a consultant psychiatrist at the Hunter New England Health Service in New Lambton, Australia.

\section{Mitchell G. Weiss}

Mitchell Weiss is based at the Swiss Tropical Institute, where his health social science research focuses on mental health and infectious and chronic disease control in low- and middle-income countries. The approach to cultural epidemiology his research group has developed includes consideration of the health impact of stigma and gender. 


\section{Introduction}

Suicides accounted for 873,000 deaths worldwide in 2002 (WHO, 2004), with an estimated 73\% occurring in developing countries (Vijayakumar, 2004). More than half of suicides globally occur in China and India, where they are also more likely to be underreported than in high-income countries. Rates in India have increased from 6.3 per 100,000 in 1980 to 10.3 in 2005 (National Crime Records Bureau MoHA, 2007). Although media, including economic and political analysis, have focussed on farmer suicides in rural India (Sridhar, 2006; Sainath, 2006), urban suicides are also a substantial problem, ranging up to 29.9 per 100,000 in Chennai and Jabalpur, and with a mean rate of 11.4 in 35 cities monitored by the Government of India (National Crime Records Bureau MoHA, 2007). In Mumbai the reported suicide rate was 7.3 in 2005. Stressors of poverty and limited livelihood opportunities in India's urban slums likely contribute to various mental health problems and suicide (Parkar et al., 2003).

American and European studies frequently assert that $90 \%$ of suicides are attributable to a pre-existing psychiatric disorder (Goldsmith 2002). While acknowledging the importance of psychiatric disorders in India and China (Vijayakumar \& Rajkumar, 1999; Phillips et al., 2007), Asian research highlights the importance of social stress and interpersonal problems (Bhatia et al., 1987; Gururaj \& Isaac, 2001; Phillips et al., 2002). Government of India statistics refer to stressful situations, (e.g., dowry, bankruptcy or changing economic status, family problems), and studies in India suggest that nearly half of suicides and deliberate selfharm cases are not associated with psychiatric disorders (Parkar et al., 2006; Gururaj et al., 2001).

Psychological autopsy studies of suicide were introduced in 1958 (Shneidman \& Farberow, 1965) and are still widely used (Pouliot \& De Leo, 2006). Though acknowledging broader interests in principle, most psychological autopsies focus on making psychiatric 
diagnoses retrospectively. Silverman (2006) highlights the need for a standard language and syntax of concepts to guide research and communicate findings. Interdisciplinary and mixed quantitative and qualitative approaches, such as cultural epidemiology, provide a means of addressing the contexts and patient-identified underlying problems and causes.

Broad-based interdisciplinary approaches to explain the contexts and situations characteristically associated with suicide locally should be considered for suicide prevention. Research has begun to respond to this need, including WHO’s SUPRE-MISS collaborative studies (Bertolote et al., 2005). Local contexts of suicide are also relevant for new models of community mental health, which recognize the role of social stress and cultural values.

In Mumbai, life and stress in urban slums underscore the importance of context. This study aimed to identify the social and cultural basis of patient-identified underlying problems and perceived causes of suicide using a verbal autopsy (VA) approach to consider a broader range of concerns beyond the diagnostic interests of a traditional medical or psychiatric paradigm.

\section{Methods}

\section{Setting}

This study was conducted in the slum community of Malavani (population 150,000) at Malad, a suburb of Mumbai. The community includes 60.1\% Muslims, 38.2\% Hindus and 1.7\% Christians. Many residents are migrants from all parts of India seeking work in Mumbai. The quality of housing and infrastructure are typically inadequate and unhygienic, but may vary considerably. Unemployment, alcoholism, domestic violence, and other problems of slum communities remain formidable (Parkar, et al., 2003). According to local police records for 2003, the suicide rate in Malavani was approximately 12.0 per 100,000, with a notable male:female ratio of 1:1.45. 


\section{Instrument}

An EMIC interview (Explanatory Model Interview Catalogue) is a semi-structured instrument for cultural epidemiological assessment that examines categories and narrative accounts of the experience, meaning, and behaviour associated with a health problem, in this case suicide. EMIC interviews elicited both categorical data and prose narrative accounts (Weiss, 2001). This approach was previously used in previous clinical studies of deliberate self-harm (DSH) at the KEM Hospital, Mumbai (Parkar et al., 2006). The interview for this study was adapted for VA with family members and close friends of persons who died by suicide. Open-ended and category-specific questions based on the above framework were formulated to identify and clarify the role of situational contexts, patterns of distress, and perceived causes of suicide. The interview examined underlying problems (i.e., locally attributed patterns of distress associated with the suicide) and other perceived causes of suicide for this person.

\section{Design}

Persons who had died from suicide during the period from 1997 to 2003 were identified from police records and traced in the community with the help of community workers. First-degree relatives or close friends who knew the deceased's life history were asked to participate in the study. Families typically decided who would represent their views as a respondent. During the interview, however, only the respondent and no other family or friends were present. Interviews were administered by a research psychiatrist after training in the use of the EMIC interview. Most were conducted in the health centre. Ethical approval of the KEM Hospital ethics committee was obtained and confidentiality of interviews was maintained. 


\section{Data management and analysis}

The data set included categorical data for quantitative analysis and prose narratives that were coded for thematic content, based on the item of the EMIC interview that elicited the narrative. Data for quantitative analysis were entered into a computer using Epi Info software (version 6.04d), programmed with logic and range checks. These data were imported into SAS for analysis. Qualitative data were managed and analyzed using the MAXqda program. This qualitative software referenced sections of the narrative to questions of the EMIC interview, making them readily accessible for analysis of thematic content. Variables from the quantitative data set were also imported into the programme, so that narratives and segments from subsets of the sample could be selected and compared.

Categorical variables from the EMIC interview were analysed with descriptive statistics to identify the distribution of prominent features of the context, family-identified problems, and locally perceived causes of suicide. Narratives elaborated accounts of problem-related experience, meaning, and behaviour.

\section{Results}

\section{Socio-Demographic Profile}

From legible police records 96 cases of suicide between 1997 and 2003 were identified, and 76 index suicide cases with traceable survivors who agreed to be interviewed were studied (79.1\%). Most suicides were in the 21-28 year age group. This age distribution was similar for men and women (Table 1). Among younger cases, more women had died by suicide, and among older cases, more men. Most women who died by suicide were housewives, and they had less education compared with men. Fewer Muslims were identified as suicides (19.7\%). Most men and women had low income. The relationship of respondents 
to suicide cases included parents (22.4\%), in-laws (22.4\%), siblings (19.7\%), spouse (17.1\%), and others $(18.4 \%)$.

\section{\{Table 1 about here\}}

The most common suicide method was burning (56.6\%), especially for women (65.1\%). Poisoning was next most frequent (18.4\%), and hanging was reported by $15.8 \%$, more common in men (24.2\%). One or more prior attempts were reported for $35.5 \%$ of the sample, and for this subgroup, self-poisoning was a common means of that prior attempt (45.5\%), either with a toxic substance (27.3\%) (mainly cholinesterase inhibiting insecticides) or drug overdose (18.2\%) (mainly benzodiazepines).

\section{Identified underlying problems}

Categories of distress that indicate the underlying problems associated with suicide are summarized in Table 3. Mental health or emotional problems (typically elaborating on varieties of tension) was the most frequently reported overarching category, conceived in local terms. Although the nature of these problems reflected gender-specific differences, both men and women referred these problems. Interpersonal problems, especially with a spouse, were also frequently reported by men and women. Behavioural problems—referring to alcohol, smoking, gambling, and fighting — were important features of male suicides. Inability to fulfil expectations, referring to job or financial responsibilities, was also more frequently associated with male suicides. Victimization, both physical and verbal abuse, was less frequently reported but more frequently associated with female suicides (significantly for verbal abuse and highly suggestive for physical abuse).

\section{\{Insert Table 2 about here\}}




\section{Perceived causes}

Questions about perceived causes provided respondents with another way of describing features of the underlying problems they associated with suicide (Table 4). They referred to an identified direct causal relationship, rather than an associated ongoing problematic situation, though the distinction is subtle and fluid. More clearly, however, these questions provided respondents with an opportunity to elaborate on their ideas about their relatives' suicide. The most frequently reported perceived causes were social, highlighting the role of marital conflicts. Although mental tensions among patterns of distress were reported by nearly three-quarters of the sample, they were identified as causes by about onequarter. Alcohol, on the other hand, was more likely to be identified as causal when it was identified as an associated problem.

\section{\{Table 3 about here\}}

\section{Prominent themes in explaining suicide}

Tension

Tension was a pervasive issue, a vernacular expression of emotional “problem”. For many respondents mental tension did not necessarily mean mental illness. "I do not think people have mental illness; people generally get shocked by certain things and then decide to end their life. It is tension not illness.” They might also associate it with mental illness, though regarding it as something less. In that regard, mental illness is a more mysterious and alien term, but tension is familiar, something people know very well, and something they are comfortable to talk about: “I don’t know about mental illness. They do have some tension, because of which they commit suicide." Other respondents referred to tension as an equivalent 
term for mental illness: "Yes they do have some mental illness like depression or some sort of tension.”

Impact of problem drinking

Survivor accounts emphasized the role of problem drinking for men, which led to irrational, self-destructive behaviour. These accounts invariably attributed suicide to the addictive habit and the effects of alcohol. A young woman explained the death of her brotherin-law:

He drank alcohol, smoked cannabis and took tablets. He quarrelled with us frequently about money and had threatened to kill himself.

Accounts of women affected by alcohol mainly referred to victimisation from their husband, father, brother, or other important men in their life. A 19-year-old woman blamed her alcoholic father for her mother’s suicide:

My father was a drinker. He would verbally abuse my mother with foul

language. When he drank, he would also hit her. She had threatened many times before that if he didn't stop fighting with her, she would burn herself.

Marital problems

Interpersonal problems in marital relations were frequently identified as causes of suicide, especially for women. A respondent described how her sister had been harassed by her husband.

She must have committed suicide in fear because he had threatened her and told her not to come back home, or else he would beat her. She must have felt there was no other way out. 
Financial problems and limited livelihood opportunities

Poverty, unemployment, financial difficulties, and limited opportunities were frequently identified in explanations of suicide, often closely related to drinking, marital problems, and other issues. A young man explained how his 50-year-old uncle had been troubled by his financial problems, and how this led to drinking and marital conflict.

He became very tense and worried about his financial problem. He did not have a good business, and he drank a lot of alcohol in frustration. His wife must have berated him, shaming him before he committed suicide.

\section{Physical health problems}

Suicide-related emotional distress was associated with various physical health problems. The impact of physical disorders referred occasionally to the discomfort of the condition, as was the case in describing tension from chronic piles. Physical health problems usually referred to serious conditions with social and cultural meaning associated with stigma and shame including tuberculosis, HIV/AIDS, epilepsy, and cancer. In describing the suicide of her 50-year-old daughter, an 80-year-old woman explained:

She had cancer of the uterus. We had tried all possible treatments, but she was constantly in pain. Then, about 5-6 months ago, she also came to know she had AIDS. She told us that people had told her not to come near to them. People also stopped coming to our house to eat or to drink.

Mental health problems

The concept of mental illness arose in several different contexts. It was a recognizable concept, and many respondents commented on whether it was, or was not, a factor explaining 
suicide. In some accounts it was a fully satisfactory explanation. "I think the main problem was her mind was not right." And, "Mainly it was her mental illness that led her to behave the way she did.” More frequently, however, narratives considered mental illness with reference to other explanations of suicidal behaviour. "People may have mental illness but I feel there are other reasons like interpersonal problems, quarrels, and financial problems that lead a person to suicide.”

The concept of mental illness arose in various accounts of serious emotional distress. In some accounts, inability to control intense emotional experience was a defining feature of mental illness. "My sister did not have control over her anger, and so she would be having mental illness.” Respondents more typically referred to intense anger as a personality trait, rather than mental illness, which had led to suicidal behaviour.

I think the most important problem was her quick temper. Now-a-days girls get angry very fast. They don't listen to elders. Once she wanted to consume ant poison. We snatched it and stopped her.

In some accounts, mental illness as an explanation of suicide was mediated by the distress it causes. In other accounts, it was a motivation for irrational suicidal behaviour more directly, or it explained a process that resulted in suicide. In its association with irrational behaviour, mental illness was an alternative explanation to possession or sorcery. It was more likely to be considered a chronic condition, rather than an acute response to some particular stressor. "I do not think that people have a mental illness. They get shocked by certain things and decide to end their life.” For others, however, mental illness was considered to be an enduring predisposition that explained suicide as an ultimate outcome.

She was having some mental illness even before our marriage. She was given medications, but since she did not take them properly, how could she get well? She would run away from the house and wander around. She heard voices. 
Possession and sorcery

Supernatural explanations were included in the responses of a substantial minority of respondents. Accounts of possession refer to the influence of a ghost or demon. These included the seizures of a woman with epilepsy, the influence of a ghost who died in a similar way, a sudden change in behaviour after returning from the village, and as a way of explaining an unacceptable or otherwise unexplainable death. The family of a woman with epileptic seizures assumed she had been possessed by a devil (shaitan) for many years.

The surviving family of a young boy who had left Mumbai to visit his village assumed that something ‘supernatural’ (daivi) must have happened.

He was absolutely fine for 6 days after he went to the village to pick up his wife. One of our relatives had to accompany him. I think in the village he must have gone by the river where they cremate bodies, and he was possessed by a demon.

In a case of a double suicide, a woman who had begun to behave strangely and had become intensely fearful over the course of a year explained to her family that she had been possessed. The family believed that it was her brother, who had died in a car accident a year earlier, who was making trouble for her. They gave several additional reasons for concluding that the death of mother and child had been the work of demons.

When she burnt herself she was dressed beautifully in a good sari with all her gold ornaments and with our daughter. How can all this have been possible? Who gave her all these ideas? I believe it must have been demons.

Others, like the family in the above account, also gave specific reasons for their explanation, as to who was responsible for the sorcery, either relatives or outsiders. Others might also refer vaguely to unknown persons without anyone in particular in mind. The 
possession might also be a product of a family dispute, or come as retribution. In one account, the deceased was a man who had committed murder. He, with some of his drunken friends had allegedly killed his own cousins and some of their relatives. He had been in prison for 6 months 50 years earlier. "Sometimes we feel that those relatives must have done some black magic on him (karni) or must have got him possessed by a demon (bhut).”

The distinction between possession and sorcery was also blurred in some other accounts of odd behaviour prior to suicide.

Some people in our neighbourhood might have done black magic, but we can't identify anybody in particular. He had this problem for 2 years. He would roll on the floor and scream, "Leave me!" "Leave me!" Some demon might have possessed him.

For other respondents, there was no clear basis for attributing the suicide to sorcery or possession. Consideration of these perceived causes enabled them to explain what would otherwise be unexplainable or unacceptable.

\section{Discussion}

This study indicated the range of community ideas and explanations of suicide, based on accounts of survivors who were most directly affected by the loss of the deceased. Findings indicated the role of particular social contexts. The approach and methods used in this study complement standard methods of psychological autopsy, which typically emphasize diagnosis rather than social and cultural context. Harris and Barclough (1997) focus exclusively on retrospective diagnosis in an effort to explain suicide in their metaanalysis of suicides as an outcome of mental disorders, concluding with a frequently cited finding that $90 \%$ of all suicides result from psychiatric disorders. In a critical assessment of this approach, recognizing that serious depression is far more common than suicidal 
behaviour, Pouliot and De Leo (2006) argue that relying too much on a medical diagnostic paradigm is unsatisfactory. It does not explain why some people and not others with the same disorder are suicidal and why rates of suicide differ in different societies and cultural groups. We found that community explanations for suicide were regarded as a complementary framework to mental disorders by some respondents and an alternative framework by others. Accounts of survivors may also be shaped by their relationship to the deceased, suggesting the need to compare different respondents for an index suicide.

Findings also indicate the potential value for suicide prevention and community mental health of enhancing VA as a tool to identify cause of death in mortality studies and health demographic surveillance systems (Setel et al., 2006). More careful attention to suicide would help to overcome limitations for mental health of mortality studies in transient slum communities, arising from problems tracing and locating survivors of suicide among family and friends. The concept of VA relies primarily on verbal accounts of a death from survivors who provide a clinical history, rather than analysis of organs and tissue. It has become an important tool for health system planning, and efforts continue to refine the approach (Baiden et al., 2007). Two main approaches use questionnaires and assessing signs and symptoms to produce narratives; combining categorical and narrative data are regarded as particularly effective (Gajalakshmi \& Peto, 2006). Recognized as a means of identifying suicides, VA has been used for that in India (Kumar et al., 2006). Psychological autopsy was developed as a specialized approach, using methods comparable to VA, but typically concerned more exclusively with explaining the reasons for suicide with reference to a psychiatric framework based on search for evidence of a retrospective diagnosis.

As an alternative to a focus on retrospective diagnosis, our approach to sociocultural autopsy considers the context and underlying problems from survivors' accounts that explain a death from their point of view. It is rooted in the framework of cultural epidemiology and 
experience in clinical studies of deliberate self-harm (Parkar et al., 2006). Based on critical consideration of commonly used methods of VA and psychological autopsy, the approach overcomes limitations in their use to explain suicides (Figure).

\section{\{Insert figure about here\}}

The concept of psychological autopsy with its focus on the diagnosis of high-risk disorders is of course most appealing in clinical psychiatry, facilitating diagnosis and treatment of psychiatric disorders. Popular accounts in newspapers, literature, films, and so forth are far more likely, however, to focus on situations, underlying problems, and stressors—-not only in Asia but also the West (Anderson, 2008). Our findings show that this is how survivors of the suicide of a friend or relative in this urban Mumbai slum community explain their loss. A persisting critique of psychiatry, recently re-emphasized, questions the basis and threshold for distinguishing sadness of life experience from clinical depression (Horwitz \& Wakefield, 2007). This critique, however, may be countered by an argument that holds serious treatable depression, especially when associated with suicidal behaviour, may be too easily dismissed as sadness without clinical significance. Questions remain in any case about how to respond to such intense sadness that is closely linked with social determinants, regardless of whether it is classified as a dysphoric life experience or a depressive disorder.

\section{Environmental and ecological factors}

Attention to environmental factors highlighted the impact of poverty, deprivation and social conflicts that characterize life in this urban slum. Marital and other interpersonal conflicts, alcohol, victimization, and limited livelihood opportunities were important factors, illustrating the impact of social defeat and entrapment. Gender-related factors had distinct 
effects on men and women. Perceived cause referred to greater impulsivity among women. Poverty and unemployment more typically affected men, contributing to alcoholism and violence against women. Effects of alcohol were pervasive, affecting both men and women. Typically it is a problem for women because alcohol misuse is so frequently related to their victimization by men. This finding helps explain why marriage appears to be a risk factor for suicide among Asian women, but not men (Khan \& Reza, 2000).

Suicide studies have long associated dowry harassment and suicide (Venkoba Rao, 1965), and it has also been included as a category in national statistics among causes of suicide (National Crime Records Bureau MoHA, 2007). Nevertheless, it was not identified as a factor among any of the suicides in this poor migrant community. This finding may result from greater significance of broader livelihood concerns than dowry. One might expect dowry problems to contribute more to suicide in urban Mumbai and other areas of India among socioeconomic groups for which dowry issues are more pervasive.

The focus on stressful conditions in our findings is consistent with previous studies highlighting stressful life events preceding suicide (Vijayakumar \& Rajkumar, 1999; Cheng et al., 2000). The focus on life events detached from context, however, may fail to adequately consider the impact of the daily experience in a slum, where chronic stressors are an enduring feature of the physical and social environment. Urban health studies have emphasized the impact of such factors on mental health (Parkar et al., 2003; Harpham 1994; Harpham \& Blue, 1995).

Too narrow a focus on diagnostic risk factors obscures not only the role of enduring social stressors and acute life events, but also consideration of other potentially useful social theories of suicidal behaviour, such as social defeat and entrapment. Oliver (2000) refers to entrapment in accounting for inability to break off abusive relationships despite domestic violence. Entrapment may be a more powerful factor in suicidal behaviour when the ability to 
flee is blocked (Gilbert \& Allen, 1998), though defeat remains important for explaining depression.

\section{Means of suicide}

The availability and convenient access to lethal means are widely recognized as factors influencing the choice of methods for suicide and the outcome of suicidal behaviour (Cantor \& Baume, 1998; Lambert \& Silva, 1998). We found that environmental factors played an important role. Burning with kerosene, which is used as a cooking fuel in the Malvani community, was a frequent method for suicide among women. Hanging as a means of suicide was notably uncommon, where the roughly improvised dwellings of the unsanctioned hutments (jhopadpatis) have no ceiling fans, and hanging is more likely to result in bringing down the dwelling than a completed suicide.

Although our findings from this study show that self-poisoning was a common method for prior presentations of DSH, it was far less than the percentage of patients with self-poisoning in a study of nonfatal DSH at KEM Hospital in central Mumbai (Parkar et al., 2006), in which poisoning or overdose was pervasive (97.5\%). Among suicides we studied in Malvani, lethal means used in prior episodes of DSH were more frequent than among patients with DSH studied at KEM Hospital, suggesting that lethal means for DSH may predict higher risk for subsequent death by suicide.

\section{Implications for community mental health and suicide prevention}

This study indicates a need for broad-based strategies to prevent suicide, recognizing the limitations of case-finding and treatment and the need for new approaches that link clinical and community priorities (Bertolote et al., 2004; Rutz, 2004). For example, psychiatric consideration of alcohol dependence as a risk factor for suicide fails to capture the 
impact of this problem on those living with the problem drinker, which our findings show was an important factor contributing to suicide in the slum, where alcohol is a serious issue.

Interventions for suicide prevention should attend to local patterns of identified underlying problems and perceived needs (Runeson, 2002; Vijayakumar; John, Pirkis, \& Whiteford, 2005). Consequently, global concerns about suicide prevention need to be linked to relevant local conditions (Weiss et al., 2001). In this community, priorities include management of alcoholism and substance abuse, and victimization of women. Strengthening social support provided by community women's groups and developing job opportunities for men address relevant needs that extend well beyond health sector interests of suicide prevention and mental health.

While it has been tempting for policymakers to regard intersectoral needs as an excuse for neglecting and failing to invest in community mental health, our findings validate basic WHO definitions of health and mental health, which assert that neither should be defined as merely the absence of disease and disorder. Our study validates this point, showing it is not merely a matter of congenial social theory, but also a strategic imperative for preventing problems and promoting health in community programmes. Monitoring the local contexts of mental health problems, especially suicide, should become an integral feature of a community mental health agenda. Both mental health services and culturally sensitive social interventions are needed for suicide prevention and community mental health.

\section{Acknowledgements}

Local support was provided from a community mental health initiative of the Departments of Psychiatry and of Preventive and Social Medicine, KEM Hospital, Mumbai. Additional support was provided by the Swiss National Science Foundation. We are grateful for the cooperation of the police station in Malavani to identify suicides. Dominic Gosoniu assisted 
with statistical analysis.

\section{References}

Anderson, S. (2008). The urge to end it. New York Times Magazine. 6 July.

Baiden, F., Bawah A., Biai, S., Binka, F., Boerma, T., Byass, P., Chandramohan, D., Chatterji, S., Engmann, C., Greet, D., Jakob, R., Kahn, K., Kunii, O., Lopez, A.D., Murray, C.J., Nahlen, B., Rao, C., Sankoh, O., Setel, P.W., Shibuya, K., Soleman, M., Wright, L., \& Yang, G. (2007). Setting international standards for verbal autopsy. Bulletin of the World Health Organization, 85, 570-571.

Bertolote, J.M., Fleischmann, A., De Leo, D., Bolhari, J., Botega, N., De Silva, D., Tran Thi

Thanh, H., Phillips, M., Schlebusch, L., Värnik, A., Vijayakumar, L., Wasserman, D. (2005). Suicide attempts, plans, and ideation in culturally diverse sites: the WHO SUPRE-MISS community survey. Psychological Medicine, 35, 1457-1465.

Bertolote, J., M., Fleischmann, A., De Leo, D., \& Wasserman, D. (2004). Psychiatric diagnoses and suicide. Revisiting the evidence. Crisis, 25, 147-155.

Bhatia, S.C., Khan, M.H., Mediratta, R.P., \& Sharma, A. (1987). High risk suicide factors. Journal of Nervous and Mental Disease, 193, 83-92.

Cantor, C.H., \& Baume, P.J. (1998). Access to methods of suicide. What impact? Australian and New Zealand Journal of Psychiatry, 32, 8-14.

Cheng, A.T., Chen, T.H., Chen, C.C., \& Jenkins, R. (2000). Psychosocial and psychiatric risk factors for suicide. Case-control psychological autopsy study. British Journal of Psychiatry, 177, 360-365.

Gajalakshmi V., \& Peto R. (2006). Commentary: Verbal autopsy procedure for adult deaths. Crisis, 35, 748-750.

Gilbert, P., Allen, S. (1998). The role of defeat and entrapment (arrested Flight) in 
depression: an exploration of an evolutionary view. Psychological Medicine, 28, 585-598.

Goldsmith, S. K., Pellmar, T. C., Kleinman, A.M., \& Bunney, W.E. (eds). (2002). Reducing suicide: a national imperative. Washington, DC: The National Academies Press.

Gururaj, D., \& Isaac, M.K. (2001). Suicides-Beyond numbers. Bangalore. Bangalore: National Institute of Mental Health and Neuro Sciences.

Harpham, T. (1994). Urbanisation and mental health in developing countries, a research role for social scientist, public health professionals and social psychiatrist. Social Science and Medicine, 39, 233-245.

Harpham, T., \& Blue, I. (eds). (1995). Urbanization and Mental Health in Developing Countries. Aldershot: Ashgate Publishing.

Harris, E.C., \& Barraclough, B. (1997). Suicide as an outcome for mental disorders: a metaanalysis. British Journal of Psychiatry, 170, 205-228.

Horowitz, A.V., \& Wakefield, J.C. (2007). The loss of sadness. London: Oxford University Press.

Khan, M.M., Reza, H. 2000. The pattern of suicide in Pakistan. Crisis, 21, 31-35.

Kumar, R., Thakur, J.S., Rao, B.T., Singh, M.M., \& Bhatia, S.P. (2006). Validity of verbal autopsy in determining causes of adult deaths. Indian Journal of Public Health, 50, 9094.

Lambert, M.T., \& Silva, P.S. (1998). An update on the impact of gun control legislation on suicide. Psychiatric Quarterly, 69, 127-134.

National Crime Records Bureau MoHA. (2007). Accidental deaths \& suicides in India, 2006. New Delhi, India: Government of India.

Oliver, W. (2000). Preventing Domestic Violence in the African American Community: The Rationale for Popular Culture Interventions. Violence against Women, 6, 533-549.

Parkar, S.R., Dawani, V., \& Weiss, M.G. (2006). Clinical diagnostic and sociocultural 
dimensions of deliberate self-harm in Mumbai, India. Suicide and Life-Threatening Behavior, 36, 223-238.

Parkar, S.R., Fernandes, J., \& Weiss, M.G. (2003). Contextualizing mental health: gendered experiences in a Mumbai slum. Anthropology and Medicine, 10, 291-308.

Phillips, M.R. Shen, Q., Liu, X., Pritzker, S., Streiner, D., Conner, K., Yang, G. (2007). Assessing depressive symptoms in persons who die of suicide in mainland China. Journal of Affective Disorders, 98, 73-82.

Phillips, M.R., Li, X., \& Zhang, Y. (2002) Suicide rates in china 1995-1999. Lancet, 359, 835-840.

Pouliot, L., \& De Leo, D. (2006). Critical issues in psychological autopsy studies. Suicide and Life-Threatening Behavior, 36, 491-510.

Runeson, B.S. (2002). Suicide after parasuicide. British Medical Journal 325, 1125-1126.

Rutz, W. (2004). Suicidal behavior: comments, advancements, challenges. A European perspective. World Psychiatry, 3, 161-162.

Sainath, P. (2006). It's official: distress up, suicides appalling. The Hindu, 22 November 2006.

Schneidman, E.S., \& Farberow, N.L. (1965). The Los Angeles Suicide Prevention center: a demonstration of public health feasibilities. American Journal of Public Health, 55, 2126.

Setel, P.W., Rao, C., Hemed, Y., Whiting, D.R., Yang, G., Chandramohan, D., Alberti, K.G., Lopez, A.D. (2006). Core verbal autopsy procedures with comparative validation results from two countries. PLoS Medicine, 3, 1282-1291.

Silverman, M.M. (2006). In this issue. Suicide and Life-Threatening Behavior, 36, iii-v.

Sridhar, V. (2006). Why do farmers commit suicide? The case of Andhra Pradesh. Economic and Political Weekly, 41, 1559-1565. 
Venkoba Rao, A. (1965). Attempted suicide: an analysis of 114 medical admissions. Indian Journal of Psychiatry, 7, 253.

Vijayakumar, L. (2004). Suicide prevention: the urgent need in developing countries. World Psychiatry, 3(3), 158-159.

Vijayakumar, L., \& Rajkumar, S. (1999). Are risk factors for suicide universal? A casecontrol study in India. Acta Psychiatrica Scandinavica, 99, 407-411.

Vijayakumar, L., John, S., Pirkis, J., Whiteford, H. (2005). Suicide in developing countries (2): risk factors, Crisis, 26, 112-119.

Weiss, M. G. (2001). Cultural epidemiology: an introduction and overview. Anthropology \& Medicine, 8, 5-29.

Weiss, M. G., Issac, M., Parkar, S. R., Chowdhury, A. N. \& Raguram, R.( 2001). Global, national and local approaches to mental health. Examples from India. Tropical Medicine and International Health, 6, 4-23.

World Health Organization. (2004). The World Health Report 2004: changing history. Geneva: World Health Organization. 
Table 1. Sociocultural features of suicide sample (\%).

\begin{tabular}{|c|c|c|c|c|c|c|}
\hline \multirow[t]{2}{*}{ Sample characteristics } & \multicolumn{2}{|c|}{ Women (43) } & \multicolumn{2}{|c|}{ Men (33) } & \multicolumn{2}{|c|}{ Total (76) } \\
\hline & Number & Percent & Number & Percent & Number & Percent \\
\hline \multicolumn{7}{|l|}{ Age groups (years) } \\
\hline $10-19$ & 7 & 16.3 & 3 & 9.1 & 10 & 13.2 \\
\hline $20-29$ & 22 & 51.2 & 11 & 33.3 & 33 & 43.4 \\
\hline $30-39$ & 7 & 16.3 & 8 & 24.2 & 15 & 19.7 \\
\hline$>=40$ & 7 & 16.3 & 11 & 33.3 & 18 & 23.7 \\
\hline \multicolumn{7}{|l|}{ Marital Status } \\
\hline Never Married & 7 & 16.3 & 9 & 27.3 & 16 & 21.1 \\
\hline Married and remarried & 29 & 67.4 & 20 & 60.6 & 49 & 64.5 \\
\hline Separated or divorced & 3 & 7.0 & 2 & 6.1 & 5 & 6.6 \\
\hline Widowed & 4 & 9.3 & 2 & 6.1 & 6 & 7.9 \\
\hline \multicolumn{7}{|l|}{ Occupation } \\
\hline Labourer & 4 & 9.3 & 6 & 18.2 & 10 & 13.2 \\
\hline Unemployed & 6 & 14.0 & 7 & 21.2 & 13 & 17.1 \\
\hline Self employed & 1 & 2.3 & 11 & 33.3 & 12 & 15.8 \\
\hline Housewife & 23 & 53.5 & 0 & 0.0 & 23 & 30.3 \\
\hline Service & 3 & 7.0 & 5 & 15.2 & 8 & 10.5 \\
\hline Retired & 0 & 0.0 & 1 & 3.0 & 1 & 1.3 \\
\hline Student & 6 & 14.0 & 3 & 9.1 & 9 & 11.8 \\
\hline \multicolumn{7}{|l|}{ Education* } \\
\hline None & 20 & 46.5 & 6 & 18.2 & 26 & 34.2 \\
\hline Primary & 6 & 14.0 & 8 & 24.2 & 14 & 18.4 \\
\hline Secondary (10th Std) & 14 & 32.6 & 15 & 45.5 & 29 & 38.2 \\
\hline Higher secondary (12th Std) & 1 & 2.3 & 2 & 6.1 & 3 & 3.9 \\
\hline Beyond higher secondary & 2 & 4.7 & 0 & 0.0 & 2 & 2.6 \\
\hline Uncertain & 0 & 0.0 & 2 & 6.1 & 2 & 2.6 \\
\hline \multicolumn{7}{|l|}{ Religion } \\
\hline Hindu & 27 & 62.8 & 22 & 66.7 & 49 & 64.5 \\
\hline Muslim & 9 & 20.9 & 6 & 18.2 & 15 & 19.7 \\
\hline Jain & 0 & 0.0 & 1 & 3.0 & 1 & 1.3 \\
\hline Buddhist & 7 & 16.3 & 4 & 12.1 & 11 & 14.5 \\
\hline \multicolumn{7}{|l|}{ Family Income } \\
\hline Under 2,500 & 13 & 30.2 & 11 & 33.3 & 24 & 31.6 \\
\hline 2,500 to $<5,500$ & 15 & 34.9 & 11 & 33.3 & 26 & 34.2 \\
\hline 5,500 to $<10,000$ & 11 & 25.6 & 7 & 21.2 & 18 & 23.7 \\
\hline$>=10,000$ and more & 2 & 4.7 & 1 & 3.0 & 3 & 3.9 \\
\hline Not reported & 2 & 4.7 & 3 & 9.1 & 5 & 6.6 \\
\hline
\end{tabular}

*Primary, secondary and higher secondary educational categories refer to schooling beyond the previous category, but not necessarily graduation. 
Table 2. Indicated categories of distress (\%).

\begin{tabular}{|c|c|c|c|}
\hline Label & $\begin{array}{c}\text { Women } \\
(43)\end{array}$ & $\begin{array}{c}\text { Men } \\
\text { (33) } \\
\end{array}$ & $\begin{array}{c}\text { Total } \\
\text { (76) }\end{array}$ \\
\hline PHYSICAL HEALTH PROBLEM & 27.9 & 27.3 & 27.6 \\
\hline Chronic disease (self) & 23.3 & 24.2 & 23.7 \\
\hline MENTAL HEALTH PROBLEM & 76.7 & 81.8 & 78.9 \\
\hline Tension-worry & 69.8 & 78.8 & 73.7 \\
\hline Sadness & 41.9 & 57.6 & 48.7 \\
\hline Serious mental illness (veda) & 14 & 21.2 & 17.1 \\
\hline Bereavement & 11.6 & 9.1 & 10.5 \\
\hline Other mental health problem & 16.3 & 12.1 & 14.5 \\
\hline BEHAVIOURAL PROBLEM & 60.5 & 78.8 & 68.4* \\
\hline Substance abuse (other) & 30.2 & 3 & $18.4^{* *}$ \\
\hline Substance abuse (self) & 4.7 & 66.7 & $31.6^{* * *}$ \\
\hline Other behavioral problem & 39.5 & 39.4 & 39.5 \\
\hline FAILED EXPECTATIONS & 51.2 & 84.8 & $65.8^{* * *}$ \\
\hline Job or business (self) & 7 & 63.6 & $31.6 * * *$ \\
\hline Financial problem & 30.2 & 60.6 & $43.4^{* *}$ \\
\hline Other expectations (marital, family, etc) & 16.3 & 9.1 & 13.2 \\
\hline INTERPERSONAL CONFLICT & 69.8 & 66.7 & 68.4 \\
\hline Parent & 9.3 & 18.2 & 13.2 \\
\hline In-laws & 11.6 & 3 & 7.9 \\
\hline Spouse & 46.5 & 42.4 & 44.7 \\
\hline Siblings & 4.7 & 24.2 & $13.2^{*}$ \\
\hline Other family & 9.3 & 15.2 & 11.8 \\
\hline Other interpersonal & 11.6 & 9.1 & 10.5 \\
\hline VICTIMIZATION & 44.2 & 27.3 & 36.8 \\
\hline Physical abuse & 23.3 & 6.1 & 15.8 \\
\hline Verbal abuse & 34.9 & 12.1 & $25 *$ \\
\hline MISCELLANEOUS & 25.6 & 54.5 & $38.2 *$ \\
\hline Other & 18.6 & 42.4 & $28.9 *$ \\
\hline Cannot say & 11.6 & 12.1 & 11.8 \\
\hline
\end{tabular}

Only categories reported by more than $5 \%$ of respondents are listed.

$* \mathrm{P}<.05, * * \mathrm{p}<.01,{ }^{* * *} \mathrm{p}<.001$. P-value based on Wilcoxon test for prominence of reported categories. 
Table 3. Perceived causes of suicide (\%).

\begin{tabular}{|c|c|c|c|}
\hline Label & Women(43) & Men(33) & Total \\
\hline SUBSTANCE ADDICTION & 23.3 & 54.5 & $36.8 *$ \\
\hline Alcohol & 20.9 & 54.5 & $35.5^{* *}$ \\
\hline MEDICAL-SURGICAL & 23.3 & 27.3 & 25.0 \\
\hline Medical illness & 14.0 & 15.2 & 14.5 \\
\hline SOCIAL CAUSES & 65.1 & 81.8 & 72.4* \\
\hline Problems with spouse & 37.2 & 18.2 & 28.9 \\
\hline Other family problems & 9.3 & 15.2 & 11.8 \\
\hline Work problems & 7.0 & 27.3 & $15.8 *$ \\
\hline Other interpersonal problems & 9.3 & 15.2 & 11.8 \\
\hline Financial problems - debt & 27.9 & 54.5 & $39.5^{* *}$ \\
\hline MAGIC SPIRITS & 32.6 & 36.4 & 34.2 \\
\hline Sorcery & 18.6 & 21.2 & 19.7 \\
\hline Demons & 14.0 & 24.2 & 18.4 \\
\hline PSYCHOLOGICAL & 58.1 & 45.5 & 52.6 \\
\hline Tension & 27.9 & 24.2 & 26.3 \\
\hline Personality & 41.9 & 21.2 & $32.9 *$ \\
\hline HEREDITY & 23.3 & 9.1 & 17.1 \\
\hline Heredity & 23.3 & 9.1 & 17.1 \\
\hline OTHER & 16.3 & 21.2 & 18.4 \\
\hline Other & 25.6 & 24.2 & 25.0 \\
\hline
\end{tabular}

Only categories reported by more than 5\% of respondents are listed. Group categories include contributions of all reported categories.

$* \mathrm{P}<.05,{ }^{*} \mathrm{p}<.01$. P-value based on Wilcoxon test for prominence of reported categories. 


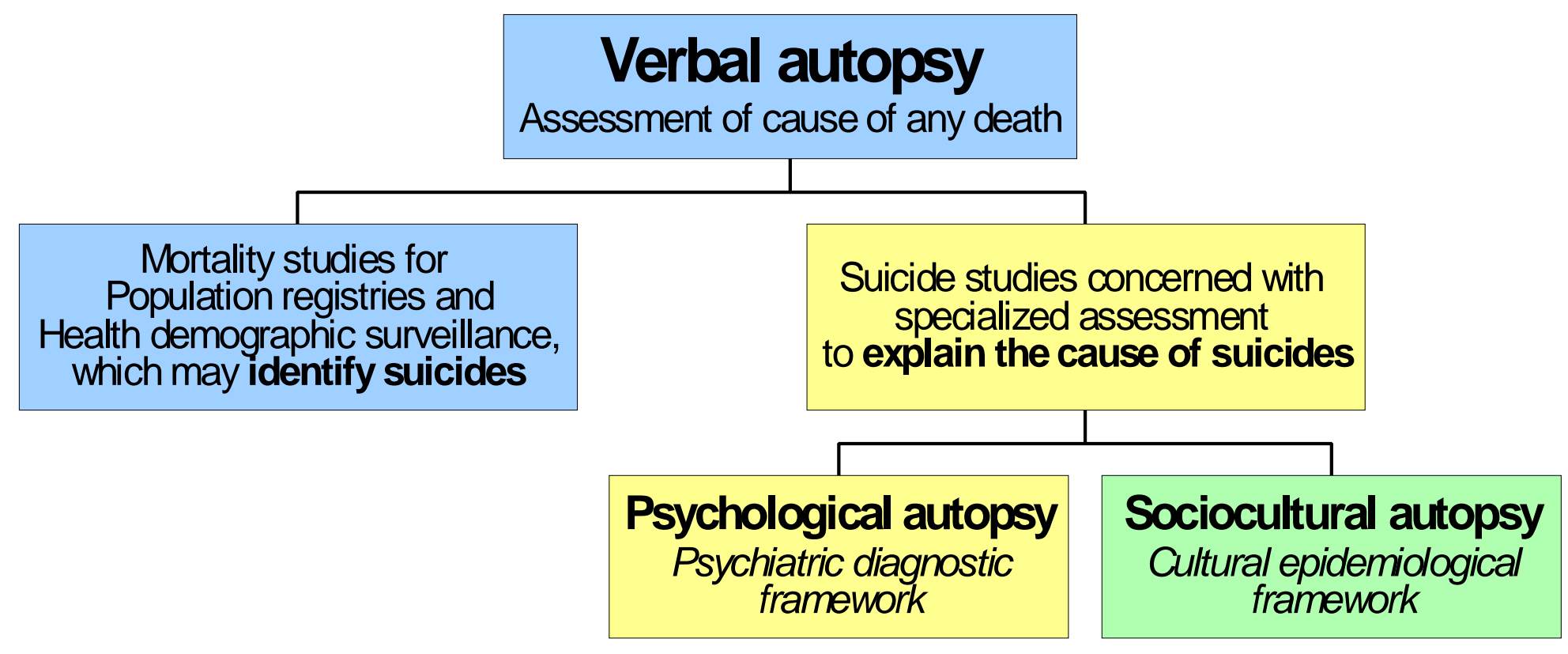

